\title{
World Journal of Pediatric Surgery Preoperative portal vein embolization followed by right hepatectomy to treat a complex common bile duct injury in a 5-year-old child
}

Juan Glinka, ${ }^{\oplus}$ Rocio Bruballa, Martin de Santibañes, Rodrigo Sanchez Clariá, Victoria Ardiles, Oscar María Mazza, Juan Pekolj, Eduardo de Santibañes

To cite: Glinka J, Bruballa R, de Santibañes $\mathrm{M}$, et al. Preoperative portal vein embolization followed by right hepatectomy to treat a complex common bile duct injury in a 5-year-old child. World $\mathrm{JnI}$ Ped Surgery 2019;2:e000033. doi:10.1136/wjps-2018-000033

Accepted 1 February 2019
Check for updates

(C) Author(s) (or their employer(s)) 2019. Re-use permitted under CC BY-NC. No commercial re-use. See rights and permissions. Published by BMJ.

Department of General Surgery, Hepato-bilio-pancreatic and Liver Transplantation Unit, Hospital Italiano de Buenos Aires, Buenos Aires, Argentina

Correspondence to Dr Juan Glinka; juan.glinka@ hospitalitaliano.org.ar

\section{ABSTRACT}

Background Common bile duct injuries (CBDIs) remains a rare but serious complication in children undergoing laparoscopic cholecystectomy (LC), with an incidence of $0.44 \%$. In severe lesions, a major liver resection may be necessary as a definitive treatment. The current principles for safe hepatectomy are mainly focused on the liver parenchyma that remains after resection. Therefore, one of the main factors related to posthepatectomy hepatic insufficiency is the quantity and quality of the future liver remnant (FLR). To achieve an optimal FLR, techniques such as portal vein embolization (PVE) are available.

Case presentation We present the case of a 5-year-old child with a severe CBDI after LC, treated with preoperative PVE followed by a right hepatectomy as definitive treatment. No reports of liver resections and PVE are described in the literature concerning the pediatric population.

\section{INTRODUCTION}

Common Bile Duct Injuries (CBDIs) remains a rare but serious complication in children undergoing laparoscopic cholecystectomy (LC), with an incidence of $0.44 \%{ }^{1}$

Within the therapeutic options, a liver resection may be necessary as a definitive treatment in severe cases. ${ }^{2}$

The current principles for safe hepatectomy are mainly focused on the liver parenchyma that remains after resection or "Future Liver Remnant" (FLR), for which techniques such as the portal vein embolization (PVE) can be used. ${ }^{3}$

We present the case of a 5-year-old child referred to our institution for the definitive treatment of a severe CBDI after LC. He was treated by preoperative PVE and right hepatectomy with Y-Roux hepaticojejunostomy reconstruction. No reports of liver resections and PVE are reported in the literature concerning pediatric population with CBDI.

\section{CASE PRESENTATION}

A 5-year-old male patient with no medical history underwent LC in another institution.
On the seventh postoperative day, he was readmitted with acute abdominal pain and fever and consequently he had a second-look exploration. The main findings were choleperitoneum and active bile leak through the common bile duct. Drainage of choleperitoneum was performed with selective catheterization of the left and right hepatic ducts with two 7 Fr silicon drainages. After surgery, the patient was referred to our department.

In our institution, the patient was admitted subfebrile and jaundiced, with four abdominal drainages that presented bilious discharge (about $250 \mathrm{~mL} / 24$ hours). An abdominal CT angiography was performed, a right hepatic artery with segmental thinning and irregularity in its route through the hepatic hilum as main finding. It has suffered a progressive worsening over time, probably due to a direct thermal injury (figure 1A). Magnetic resonance cholangiopancreatography was performed, showing a dilated left bile duct and the CBD with a filiform caliber (figure 1B). Cholangiography was performed by injection of iodinated contrast through the inserted catheters with fluoroscopic real-time observation. A predominantly left dilatation of the intrahepatic biliary tree with a stenosis at the biliary confluence was observed, without evidence of contrast outflow toward the common bile duct and/or duodenum (figure 1C). Due to the impossibility of circumventing the stenosis using interventional radiology techniques, drains were replaced by external ones ( $8.5 \mathrm{Fr}$ ), leaving the right and left ducts drained independently.

In the course of 6 months, he presented four episodes of cholangitis that required hospitalization.

A definitive surgical resolution was decided, posing as the most favorable option to perform a right hepatectomy with Y-Roux hepaticojejunostomy reconstruction. 


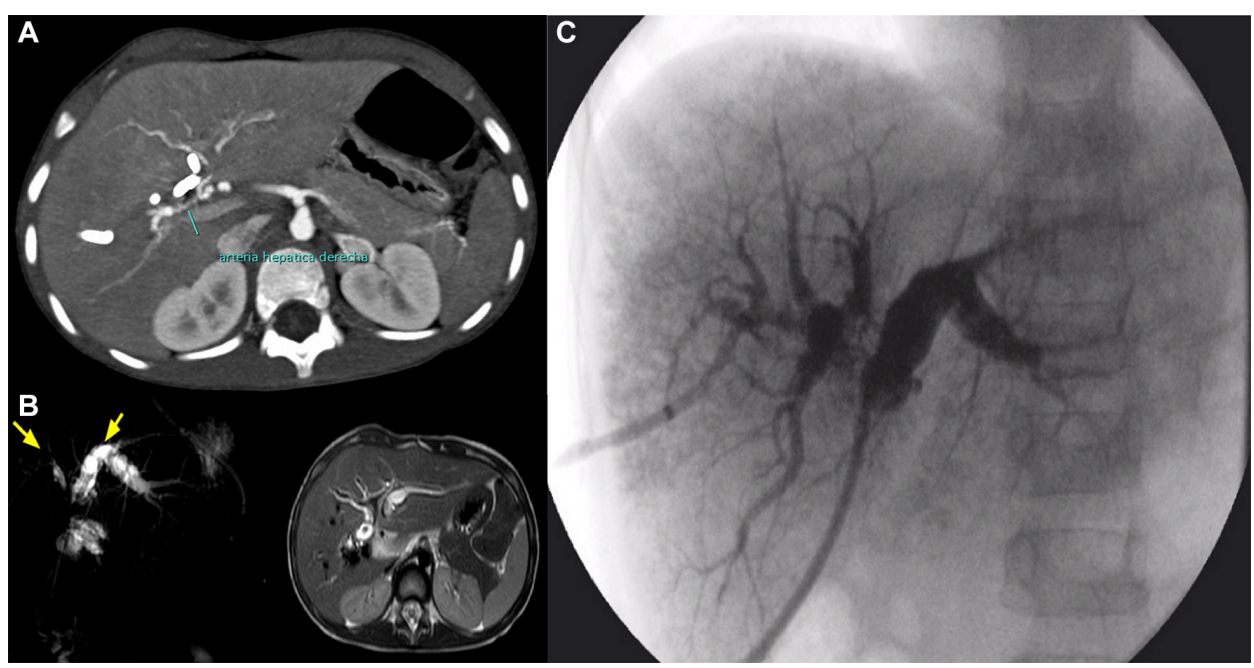

Figure 1 (A) CT angiography showing a right hepatic artery narrowed in the hepatic hilum. It is the result of a progressive worsening over time, probably due to a direct thermal injury. (B) MRCP revealing dilatation of intrahepatic bile ducts predominantly on the left. An absence of signal in the main bile duct confluence with the disengagement of both right and left ducts is observed (yellow arrows). (C) Cholangiography by injection of iodinated contrast through inserted catheters with fluoroscopic real-time observation. The study reveals stenosis of the right and left bile duct confluence, with progression toward the right duct. No contrast outflow toward the $\mathrm{CBC}$ and/or duodenum is observed. CBC, common bile duct; MRCP, magnetic resonance cholangiopancreatography.

Volumetric assessment of the liver was conducted showing a left lobe volume (segments I-II-III-IV) of 209 $\mathrm{mL}$, with a total liver volume of $610 \mathrm{~mL}$. Remnant liver volume to body weight ratio (RLV:BWR) was 1.22. In order to ensure an adequate FLR, preoperative right PVE was decided. After 30 days of PVE, new MRI volumetric assessment was performed showing left lobe volume of $353 \mathrm{~mL}$ with a total liver volume of $672 \mathrm{~mL}$; RLV:BWR of 2.07. The left liver growth achieved was $40.8 \%$ (figure 2A,B). As planned, a right hepatectomy was performed, with a biliodigestive Roux-en-Y hepaticojejunostomy using the left branch of the bile duct (figure $3 \mathrm{~A}-\mathrm{C}$ ).

The patient evolves uneventfully and is discharged on day 10 of the postoperative period.

In 2 years of clinical and imaging follow-up, the patient did not have complications leading a normal life.

\section{DISCUSSION}

CBDI may have different dimensions and complexity. Its consequences can be devastating and especially in children, where its treatment must be dynamic and precise once they are recognized.

In the available therapeutic arsenal for treating a CBDI, there are endoscopic, percutaneous, conventional procedures (biliodigestive by-pass or hepatectomies) and also the liver transplant as a last option. ${ }^{45}$ Within these tools, a biliary reconstruction is usually enough for the successful and definitive management of most of these injuries. ${ }^{6}$

For the most complex cases where there is an associated vascular lesion and/or extensive and symptomatic intrahepatic biliary stenosis as found in the patient we described (Bismuth IV/Strasberg E4), ${ }^{7}$ a biliodigestive reconstruction will tend to fail and therefore the patient would most likely benefit from a liver resection as definitive treatment. As reported by Truant et $a l^{8}{ }^{8}$ CBDI Strasberg E4 and E5 with associated injury of the hepatic artery are independent factors of the need for

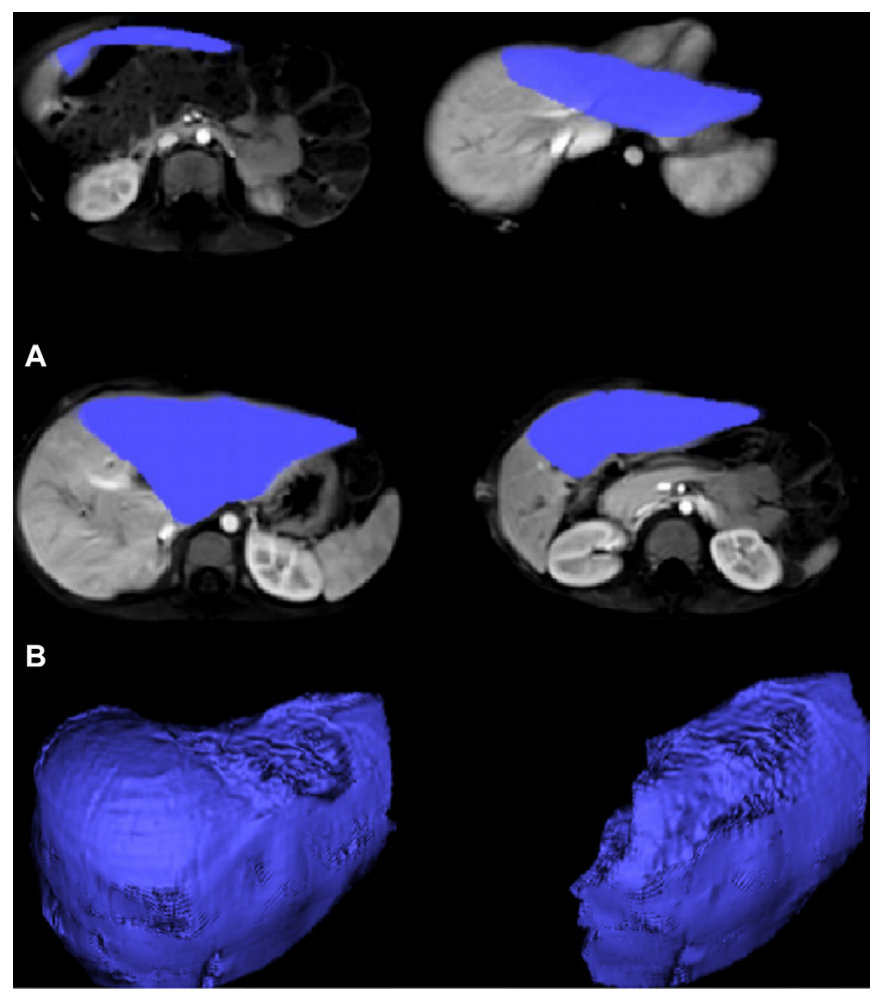

Figure 2 (A) MRI volumetric assessment after right PVE. Left hepatic lobe volume: $353 \mathrm{~mL}$. Total volume: $672 \mathrm{~mL}$. Growth 40.8\%. (B) Three-dimensional representation of volumetric measurement by MRI. Total liver and left hepatic lobe are represented on the left and right, respectively. PVE, portal vein embolization. 


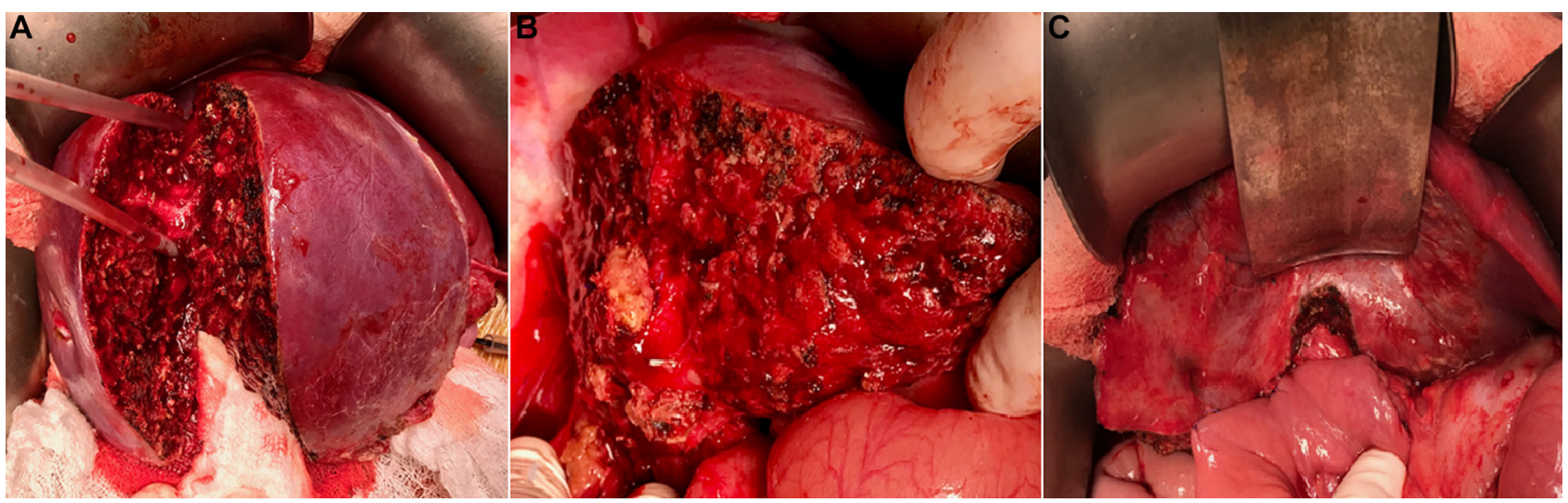

Figure 3 (A) "Hanging maneuver" during the parenchymal transection to complete the anatomical right hepatectomy. (B) Liver transection bed once hepatectomy was completed. (C) Biliodigestive reconstruction using Roux-en-Y hepaticojejunostomy.

hepatectomy (with a risk 43.3 times higher compared with patients with other lower or less complex lesions of the biliary tree). According to Li et al, up to $72 \%$ of the combination of these lesions will require a liver resection as a final treatment. ${ }^{9}$ Although there are no statistical or descriptive reports in children, the incidence of hepatectomies due to complex CBDI reported in the literature oscillates between $6 \%$ and $15 \% .^{10}$

A primary aspect to consider in order to perform a major liver resection is the FLR assessment. We were treating a fragile small child, with malnutrition and chronic inflammation due to recurrent cholangitis. So, because posthepatectomy liver failure (PHLF) was a risk that we could not run, we decide to carry out the right PVE in order to induce a compensatory hypertrophy of the FLR and make the hepatic resection safer.

After PVE, we have achieved a preoperative growth of $40.8 \%$ of the left liver (RLV:BWR 2.07). Even so, with the classic liver volumetric assessment by cross-sectional imaging that strictly encouraged us to perform a major hepatic resection, it was impossible to absolutely know whether the FLR volume would be sufficient in this particular patient from the functional point of view.

With the advent of the HIBA (Hospital Italiano de Buenos Aires) index ${ }^{11}$ (a technique of hepatobiliary scintigraphy using ${ }^{99 \mathrm{~m}}$ Tc-mebrofenin that our group described), the uncertainty in the estimation of the FLR seems to be reduced. The paradigm has changed for us from the indirect estimation of the liver function through the FLR volume and its proportion with the patient's weight toward the calculation of the true functionality of the FLR through its radionuclide excretion potential.

The HIBA index value obtained in this patient prior to PVE was 14.3 and 21.4 after PVE. According to the experience reported by Serenari et $a l^{10}$ with a HIBA index less than 14.5 , the probability of PHLF is close to $44 \%$. On the other hand, with a HIBA index higher than 15.3, only $4 \%$ of PHLF was reported. Even though this method reinforced the indication of PVE, we did not validate it at the time of this patient's treatment neither experience in the pediatric population. Until then, the routine application of this non-invasive low-cost examination could facilitate decision-making in institutions performing major liver resections, especially in these complex patients.

\section{CONCLUSION}

A major hepatectomy for the definitive treatment of a complex CBDI is exceptional. These procedures carried out in high-volume and specialized hepato-pancreato-biliary centers are safe and effective, even when strategies to increase the FLR are required. However, pediatric patients are always sensitive and must be managed in multidisciplinary teams.

Acknowledgements The authors thank Dr Juan Spina for the volumetric analysis of the liver and $\mathrm{Dr}$ Carlos Collaud for performing the hepatobiliary scintigraphy of the patient, helping us with its interpretation.

Contributors JG and RB designed the study and wrote the initial draft of the manuscript. RB, MdS, and EdS contributed to analysis and interpretation of data, and assisted in the preparation of the manuscript. All other authors have contributed to data collection and interpretation, and critically reviewed the manuscript. All authors approved the final version of the manuscript, and agree to be accountable for all aspects of the work in ensuring that questions related to the accuracy or integrity of any part of the work are appropriately investigated and resolved.

Funding The authors have not declared a specific grant for this research from any funding agency in the public, commercial or not-for-profit sectors.

Competing interests None declared.

Patient consent for publication Obtained.

Ethics approval The Ethics Committee at Hospital Italiano de Buenos Aires.

Provenance and peer review Not commissioned; externally peer reviewed.

Open access This is an open access article distributed in accordance with the Creative Commons Attribution Non Commercial (CC BY-NC 4.0) license, which permits others to distribute, remix, adapt, build upon this work non-commercially, and license their derivative works on different terms, provided the original work is properly cited, appropriate credit is given, any changes made indicated, and the use is non-commercial. See: http://creativecommons.org/licenses/by-nc/4.0/.

\section{REFERENCES}

1. Raval MV, Lautz TB, Browne M. Bile duct injuries during pediatric laparoscopic cholecystectomy: a national perspective. J Laparoendosc Adv Surg Tech A 2011;21:113-8.

2. Barbier L, Souche R, Slim K, et al. Long-term consequences of bile duct injury after cholecystectomy. J Visc Surg 2014;151:269-79.

3. van Gulik TM, van den Esschert JW, de Graaf W, et al. Controversies in the use of portal vein embolization. Dig Surg 2008;25:436-44. 
4. Ardiles V, McCormack L, Quiñonez E, et al. Experience using liver transplantation for the treatment of severe bile duct injuries over 20 years in Argentina: results from a national survey. HPB 2011;13:544-50.

5. de Santibañes E, Palavecino M, Ardiles V, et al. Bile duct injuries: management of late complications. Surg Endosc 2006;20:1648-53.

6. de Santibáñes E, Ardiles V, Pekolj J. Complex bile duct injuries: management. HPB 2008;10:4-12.

7. Strasberg SM, Hertl M, Soper NJ. An analysis of the problem of biliary injury during laparoscopic cholecystectomy. J Am Coll Surg 1995;180:101-25.
8. Truant S, Boleslawski E, Lebuffe G, et al. Hepatic resection for post-cholecystectomy bile duct injuries: a literature review. HPB 2010;12:334-41.

9. Li J, Frilling A, Nadalin S, et al. Timing and risk factors of hepatectomy in the management of complications following laparoscopic cholecystectomy. J Gastrointest Surg 2012;16:815-20.

10. Serenari M, Collaud C, Alvarez FA, et al. Interstage assessment of remnant liver function in ALPPS using hepatobiliary scintigraphy: prediction of posthepatectomy liver failure and introduction of the HIBA index. Ann Surg 2018;267:1141-7.

11. Asenbaum U, Kaczirek K, Ba-Ssalamah A, et al. Post-hepatectomy liver failure after major hepatic surgery: not only size matters. Eur Radiol 2018;28:4748-56. 